\title{
DEVELOPMENTAL RESPONSES OF SUBDOMINANT GRASSLAND SPECIES TO CURRENT WEATHER CONDITIONS AND THEIR RELEVANCE FOR ANNUAL VEgetation Changes
}

\author{
Peter Manuel Kammer \\ Institute of Plant Sciences, University of Bern, Altenbergrain 21, 3013 Bern, Switzerland; Present address: \\ BES Biologie, University of Bern, Gertrud-Wokerstr. 5, 3012 Bern, Switzerland; tel. +41316313706 , \\ fax+41316318540, e-mail kammerpe@sis.unibe.ch
}

Keywords: Air humidity, Drought, Growth rates, Page test, Temperature, Vegetation dynamics

\begin{abstract}
Year-to-year vegetation changes have been observed many times in temperate grasslands. Ordinarily, variation in annual weather patterns is considered responsible for these changes. However, the exact mechanisms of vegetation dynamics have seldom been studied. In order to analyse the direct response of plants to distinct weather situations, the shoot growth rates of three subdominant grassland species were determined during three growing seasons and tested for significant relationships to meteorological variables measured simultaneously in the study site. Half of the shoots grew in the natural community with competition from neighbouring plants. For the other half, above-ground interference was avoided by regularly clipping the surrounding vegetation. The results lead to the distinction of three different impact patterns of current weather conditions on the growth of subdominant grassland species: (i) As a consequence of extraordinary weather conditions, e.g. lasting periods of drought in the summer, plants die completely or partially or pass into secondary dormancy. Such weather situations may cause quantitative or even qualitative changes in species composition by altering the density and frequency of the species involved. (ii) Major divergences from average weather conditions, such as unusually warm or cold periods in the spring, affect the growth of subdominant species and may therefore lead to quantitative annual variation of the species involved in terms of cover or biomass. (iii) Average weather conditions with slight deviations from the long-term means of the weather variables do not produce detectable direct growth responses and therefore average weather conditions are not key factors for year-to-year variations in the quantitative or qualitative performance of subdominant species.
\end{abstract}

\section{INTRODUCTION}

Year-to-year vegetation changes have been observed many times in different vegetation types and particularly in temperate grasslands. Usually, variation in annual weather patterns is considered responsible for these changes. Numerous studies show the relationships between different weather variables and total biomass (SALA et al. 1988, TILMAN \& EL HADDI 1992, Silvertown et al. 1994, STAMPfLI 1995, DUNNETT et al. 1998), species composition (WATT 1971, Silvertown et al. 1994, StaMPfli 1995), species richness (DiERSCHKE 1985, Collins et al. 1987, Tilman \& El Haddi 1992, Rosén 1995, VAN DER MAarel 1996), or the performance of individual species expressed in terms of biomass (DUNNETT et al, 1998), cover (Albertson \& Tomanek 1965, Dierschke 1985, Collins et al. 1987, Milchunas et al. 1989, Rosén 1995), density (WATt 1971, Collins et al. 1987, Milchunas et al. 1989), and 
frequency (WATT 1971, STAMPFLI 1995, VAN DER MAAREL 1996). The correlations observed in most of these studies reflect an overall response of vegetation to weather variables, integrating different response patterns and components and providing therefore only limited insight into the mechanisms of vegetation dynamics. In fact, one has to discriminate between several possible response components: (i) Meteorological conditions may affect the intensity of flowering and seed production. This may immediately influence plant growth as a result of the resource investment in reproduction (reproduction costs). It may further cause vegetation changes with a time lag of one or more years by affecting the size of the seed pool. (ii) The course of the weather within a growing season may control the timing of phenological stages as well as the growth rates and therefore the height, the leaf area, and the biomass of single individuals or shoots. This may lead to quantitative vegetation changes by affecting the biomass and/or the cover of the species involved. (iii) Meteorological conditions may also be responsible for frequency and density changes by controlling the rate of recruitment and/or loss of shoots or individuals. (iv) And finally, they may cause local immigration and/or extinction of species and therefore lead to qualitative compositional changes.

For a better understanding of the influence of weather on vegetation dynamics in general, and especially with regard to global climate change, we should be able to estimate the significance of the different components of an overall response observed. However, only few studies tend to investigate in which way an overall response is achieved. HERBEN et al. (1995), for example, separated the overall response into the number of modules and mean module size. Phenological studies focus on one single response type, the timing of phenological stages (SPARKS \& Carey 1995, FENNER 1998, Spano et al. 1999), and especially flowering (BEAubien \& JohnSon 1994, FitTer et al. 1995, White 1995, Diekmann 1996). The present study focuses on one particular response component by investigating the potential effect of distinct weather situations on the growth of reproductive and vegetative shoots of subdominant grassland species. In order to separate weather-induced growth responses from responses due to other factors, particularly interactions with neighbouring plants, the growth of shoots in the stand was compared with the development of shoots growing without surrounding above-ground vegetation.

\section{METHODS}

\section{Study site}

The investigations were carried out in a grassland on a SSE-facing slope of $27^{\circ}$ at an elevation of $560 \mathrm{~m}$ in Bremgarten near Bern (Swiss Midlands; $46.58 \mathrm{~N}, 7.26 \mathrm{E}$ ). The study site is mown once a year at the beginning of July by local farmers. It has not been fertilized since 1958 and it is of rather low productivity. The sward is relatively open, and vascular plants cover $82.2 \%$ (mean cover value of ten $1 \mathrm{~m}^{2}$-plots sampled at the beginning of June 1992, 1993, and 1994; KAMMER 1997). Bromus erectus HUDS. is the dominating species occupying $21.7 \%$. Festuca rubra L. is the second most important grass of the stand and covers $10.6 \%$. The gaps between the tussocks of these dominating grasses are colonized by numerous herbs, the most frequent among them are Achillea millefolium L., Centaurea jacea L., Galium album MiLL., Hippocrepis comosa L., Knautia arvensis (L.) CoUlt, Pimpinella saxifraga L., Plantago lanceolata L., Rumex acetosa L., Salvia pratensis L., and Thymus pulegioides L. (KAMMER 
1998). Average species richness is about 23 species per $\mathrm{m}^{2}$. Syntaxonomically, the stand corresponds to Mesobromion association (ELLENBERG 1996).

The climate of the Bern region is temperate (mean annual temperature $8.6^{\circ} \mathrm{C}$ ) and relatively humid (mean annual precipitation of $1059 \mathrm{~mm}$ ). The warmest month is July with a monthly mean temperature of $17.9^{\circ} \mathrm{C}$, January is the coldest month $\left(-0.3^{\circ} \mathrm{C}\right)$. Precipitation is evenly distributed throughout the year with a slight minimum in winter. During the growing season (April to October) no monthly mean sum falls below $80 \mathrm{~mm}$. These values are 20 -yr means (1972-1991) obtained from the nearest meteorological station $5.5 \mathrm{~km}$ from the study site (Bern-Liebefeld).

\section{Vegetation data}

The development of the shoots of three herbs was studied: Centaurea jacea, Leucanthemum vulgare LAM., and Salvia pratensis. These species are uniformly distributed in the community under study but are not dominant; they cover $3.3 \%, 0.5 \%$, and $4.7 \%$, respectively (mean cover values of ten $1 \mathrm{~m}^{2}$-plots sampled at the beginning of June 1992, 1993, and 1994; KAMMER 1997). To provide a size-biomass relationship, one hundred shoots per species at different developmental stages were cut directly above the ground and phenometric variables (total height measured to the nearest $\mathrm{mm}$, number of lateral branches, leaves, and reproductive organs) were determined. In order to ensure the applicability of the phenometry-biomass relationship throughout the growing season, the shoots were cut at five different times between April and October 1992, and again three times in 1993. Afterwards the cut shoots were oven-dried at $105^{\circ} \mathrm{C}$ for ca. $20 \mathrm{~h}$ and the dry weight was taken to $0.01 \mathrm{~g}$. The generative organs were defined as flower verticils for Salvia and capitula for Centaurea and Leucanthemum. The relationship between phenometric variables and dry weight was calculated using multiple regression. Two (Salvia) or three (Centaurea and Leucanthemum) phenometric variables accounted for $78 \%$ to $94 \%$ of the variance in dry weight (KAMMER 1997).

In the stand under study, 20 individuals per species were marked with small plastic rings (thereafter called "in situ plants"). During the growing seasons (April - October) in 1992, 1993, and 1994 phenometric data of one marked shoot per individual were collected at intervals of 6 to 8 days (thereafter called "observation periods"). Growing seasons were subdivided into spring periods with four to six data collection events (Table 1), summer periods, and autumn periods (five to seven events each). The multiple regression equation for each species allowed the calculation of the dry weight of the shoots for every observation time. Absolute growth rates were calculated as follows:

growth rate $=\left(W_{2}-W_{1}\right) /\left(t_{2}-t_{1}\right)$

where $W_{1}$ is the calculated dry weight of the shoot at time $1\left(t_{1}\right)$ and $W_{2}$ is the weight at time $2\left(t_{2}\right)$.

In the summer of 1991, seeds of each species were collected in the study site. At the beginning of February 1992, these seeds were put on the soil surfaces of pots filled with sandy soil, equivalent to the soil type of the grassland under study. Several pots per species were placed in an open field nursery at the Botanical Garden of the University of Bern. To keep the seeds and the soil humid, the seeds were covered with a thin layer of sand and the gaps between the pots were also filled with sand. About sixty days later, at the end of April, the most robust 
Table 1. Structure of the data: observation periods (periods; numbers roughly correspond to weeks of the year), number of periods $(k)$, and number of shoots analyzed $(n)$ for (a) transplants and (b) in situ plants. Abbreviations: C.j.-Centaurea jacea, L.v. - Leucanthemum vulgare, S.p. - Salvia pratensis.

periods $\begin{gathered}\text { Spring } \\ \ldots\end{gathered} \quad n \quad$ periods $\begin{gathered}\text { Summer } \\ -\end{gathered}$

$\begin{array}{lllllllllll}\text { (a) transplants } \\ \text { C.j. } & 1993 & 17-20 & 4 & 13 & 32-37 & 6 & 17 & 38-43 & 6 & 17 \\ & 1994 & 16-20 & 5 & 13 & 29-33 & 5 & 3 & 34-38 & 5 & 3 \\ \text { L.v. } & 1993 & 15-18 & 4 & 9 & 32-37 & 6 & 11 & 38-43 & 6 & 11 \\ & 1994 & 12-17 & 6 & 15 & 29-33 & 5 & 10 & 34-38 & 5 & 10 \\ \text { S.p. } & 1993 & 16-19 & 4 & 11 & 32-37 & 6 & 19 & 38-43 & 6 & 19 \\ & 1994 & 15-19 & 5 & 16 & 29-33 & 5 & 19 & 34-38 & 5 & 19\end{array}$

(b) in situ plants

\begin{tabular}{lcccccccccc} 
C.j. & 1992 & $17-21$ & 5 & 9 & $31-37$ & 7 & 10 & $38-44$ & 7 & 10 \\
& 1993 & $17-20$ & 4 & 10 & $32-37$ & 6 & 16 & $38-43$ & 6 & 16 \\
& 1994 & $16-20$ & 5 & 9 & $29-33$ & 5 & 15 & $34-38$ & 5 & 15 \\
L.v. & 1992 & $16-21$ & 6 & 12 & $31-37$ & 7 & 9 & $38-44$ & 7 & 9 \\
& 1993 & $15-18$ & 4 & 6 & $32-37$ & 6 & 15 & $38-43$ & 6 & 15 \\
& 1994 & $12-17$ & 6 & 10 & $29-33$ & 5 & 16 & $34-38$ & 5 & 16 \\
S.p. & 1992 & $17-20$ & 4 & 8 & $31-37$ & 7 & 20 & $38-44$ & 7 & 20 \\
& 1993 & $16-19$ & 4 & 9 & $32-37$ & 6 & 18 & $38-43$ & 6 & 18 \\
& 1994 & $15-19$ & 5 & 7 & $29-33$ & 5 & 20 & $34-38$ & 5 & 20 \\
\hline
\end{tabular}

plantlets were transplanted separately in pots filled again with the same type of soil. These pots were replaced in the nursery and the juvenile plants were irrigated when necessary. In mid-September 1992, 20 mature rosettes of basal leaves of Centaurea and Salvia, and 16 of Leucanthemum were planted in monospecific lines at intervals of $50 \mathrm{~cm}$ in the grassland under study (thereafter called "transplants"). The distance between the two lines was $2 \mathrm{~m}$. This plantation design ensured that the transplants did not shade each other during the whole experimental period of two years. Before the transplantation, the vegetation of the area was clipped to a height of $2 \mathrm{~cm}$; directly after the transplantation the transplants were irrigated once. Afterwards, irrigation was no longer necessary since rainfall in the subsequent weeks was rather high. During the experimental period, the vegetation around the transplants was cut regularly, i.e. when its height reached $5 \mathrm{~cm}$, to prevent shading and shoot competition. In the 1993 and 1994 growing seasons, phenometric data of one marked shoot per transplant were collected at the same time as for the in situ plants.

During the observation periods some shoots were heavily disturbed by common voles or phytophagous insects, others showed extensive growth, incurred damages, or lost their marking rings (KAMMER 1997). For these reasons, only a part of the marked shoots were available for data analyses (Table 1).

\section{Weather data}

From the spring of 1992 to the autumn of 1994 the following weather variables were measured continuously in the stand and in the open area around the transplants: soil 
(a) 1992

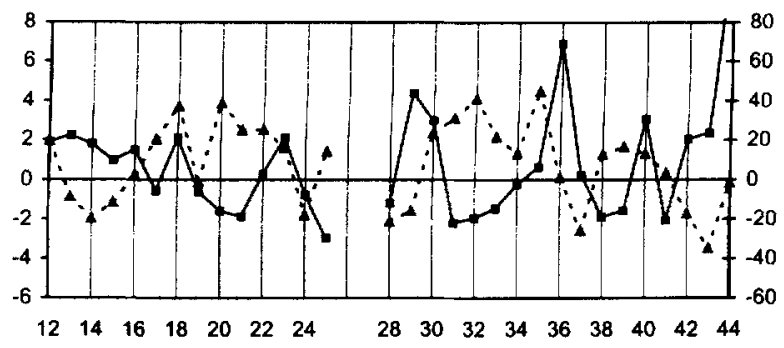

(b) 1993

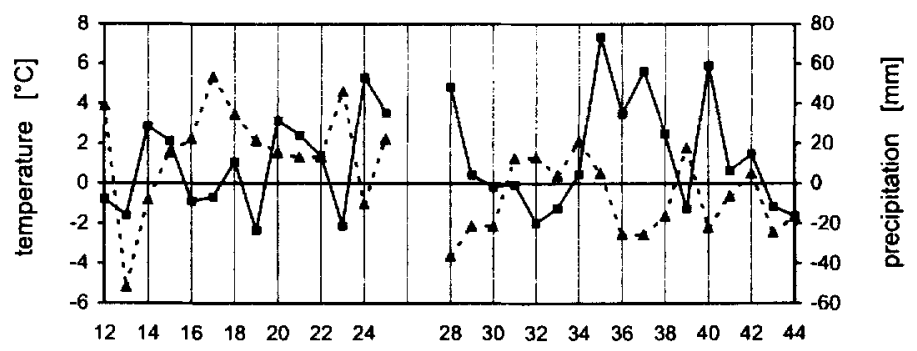

(c) 1994

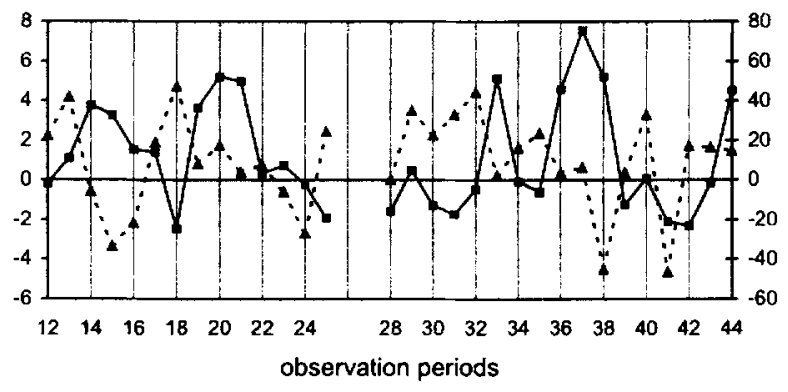

-... temperature precipitation

Fig. 1. Temperature and precipitation conditions from mid-March (period 12) to the end of October (period 44) in (a) 1992, (b) 1993, and (c) 1994 compared to the 20-yr means (1972-1991). Deviations of the mean values per observation period of 1992, 1993, and 1994 from the 20-yr means for the corresponding periods. Data from the meteorological station at Bern-Liebefeld.

temperature ( $5 \mathrm{~cm}$ below ground), temperature of soil surface, air temperature ( 5 and $15 \mathrm{~cm}$ above ground), photosynthetically active radiation (PAR, $5 \mathrm{~cm}$ above ground). Due to technical problems, relative air humidity could not be measured in the open area but was measured in the stand $(15 \mathrm{~cm}$ and $200 \mathrm{~cm}$ above ground). The temperatures were measured with thermocouples (type $\mathrm{K}$ ) sealed in plastic tubes with $\mathrm{Cu} / \mathrm{Zn}$-points. Skye SKP 210 sensors were used for PAR (Skye Instruments, Llandrindod, UK). Relative air humidity was measured with a capacitive Skye rF sensor ( $15 \mathrm{~cm}$ above ground) and with a capacitive Rotronic MF 100 sensor (200 cm above ground, Rotronic AG, Bassersdorf, $\mathrm{CH}$ ). 


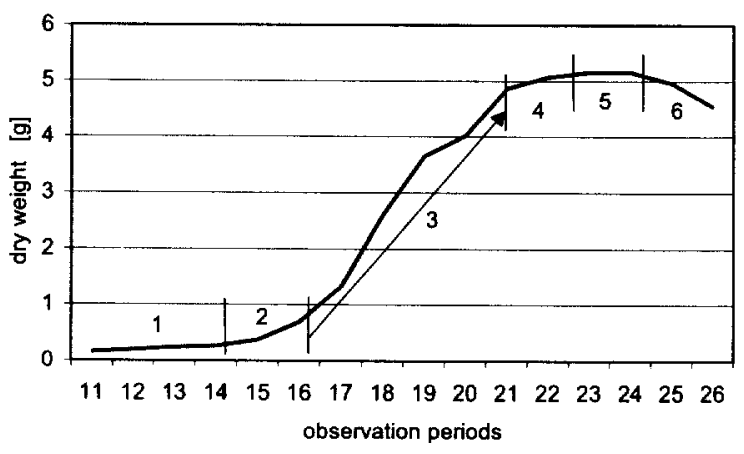

Fig. 2. Growth (calculated total dry weight per period) and phenological development of a reproductive Centaurea jacea shoot (in situ individual) during the spring of 1993. Phase 1: vegetative growth of basal rosettes (forming of basal leaves); phase 2: onset of shoot growth, forming of flower buds; phase 3: main phase of growth (elongation of internodes, branching, formation of cauline leaves); phase 4: termination of the main phase of growth, opening of flower buds; phase 5: flowering, maximum biomass; phase 6 : fruiting, dieback of basal and inferior cauline leaves.

period and compared with the corresponding values in 1992, 1993, and 1994 (Fig. 1).

Relative air humidity $15 \mathrm{~cm}$ and $200 \mathrm{~cm}$ above ground were highly correlated with each other and, on average, relative humidity in the canopy $(15 \mathrm{~cm})$ was only slightly higher $(2 \%$ to $6 \%$ ) compared to that measured above the stand $(200 \mathrm{~cm})$. Since in an open grassland there is hardly any difference in relative air humidity between $15 \mathrm{~cm}$ and $200 \mathrm{~cm}$ above ground (STOUTJESDIJK \& BARKMAN 1992), the $200 \mathrm{~cm}$ values were used to estimate the air humidity regime in the open area around the transplants.

\section{Data analysis}

Only the main phase of growth consisting of the elongation of internodes, branching, and formation of cauline leaves on reproductive shoots (phase 3 in Fig. 2) was analyzed for the spring periods. In the summer/autumn periods, the investigations were limited to vegetative shoots, i.e. basal rosettes. Here two seasons were distinguished: summer periods with daily mean temperature above $15^{\circ} \mathrm{C}$ and autumn periods with lower temperatures.

The data structure (Table 1) consisted of a short time-series with four to eight observations, small sample sizes (three to 20 shoots per species) and several interrelated weather variables. Data do not meet the assumptions of common statistical procedures and tests, in particular multiple regression techniques. For that reason the Page test was chosen as a robust alternative. This test starts out from a randomized complete block design. It is also appropriate in situations where a single subject (e.g. an individual shoot) is a block (DANIEL 1990). Page test is a nonparametric analogue of the parametric two-way analysis of variance and it is based on ranks. The procedure is specifically designed to detect one-sided alternative hypotheses in 
cases where treatments have a natural ordering; e.g. the treatments might represent progressively increasing temperatures or precipitation sums (CYTEL 1995). The basic model of the Page test is as follows:

$$
U_{i j}=\mu+\beta_{i}+\tau_{j}+\varepsilon_{i j},
$$

for $i=1,2, \ldots n$ (number of blocks), and $j=1,2, \ldots k$ (number of treatments), where $\mu$ is the overall mean, $\beta_{i}$ is the time-independent block effect, $\tau_{j}$ is the treatment effect, and the $\varepsilon_{i j}$ 's are identically distributed unobservable error terms from an unknown distribution with a mean of 0 (CYTEL 1995). The null hypothesis of no treatment effect is stated as

$H_{0}: \tau_{1}=\tau_{2}=\tau_{k}$

The one-sided alternative hypotheses are

$$
H_{1}: \tau_{1} \leq \tau_{2} \leq \tau_{k},
$$

and

$H_{1}^{\prime}: \tau_{1} \geq \tau_{2} \geq \tau_{k}$

The test statistic is

$$
P A=R_{1}+2 R_{2}+\ldots+k R_{k}
$$

where $R_{1} \ldots R_{k}$ are the treatment rank sums. The treatment rank sums are weighted by the index of their position in the ordering specified by $H_{1}$ or $H_{1}^{\prime}$ respectively. The observed $P A$-values were converted into standardized $P A$-values distributed approximately as the standard normal (DANIEL 1990). The Page tests were performed with StatXact 3 (CYTEL 1995), a software package for nonparametric statistics. Exact $P$-values were computed. As several (11) tests of significance were carried out simultaneously the significance level was adjusted for the Bonferroni correction (LEGENDRE \& LEGENDRE 1998). Standardized $P A$-values with $P$-values $\leq 0.0045$ were considered significant corresponding to a significance level of $P \leq 0.05$ for single tests. Significant, positive standardized $P A$-values provide evidence in favour of $H_{1}-$ suggesting positive relationships between weather conditions and growth rates - and significant negative standardized $P A$-values indicate that $H_{1}^{\prime}$ is true.

As a measure for the developmental variability among the different shoots of a species, the mean variation coefficient based on ranks of the growth rates was computed. To that end, the growth rates of each shoot were ranked separately from the smallest to the largest corresponding to the first step in the Page test. Tied observations were given the mean of the rank positions for which they are tied. Then, variation coefficients for each shoot were calculated based on ranks. Finally the shoot variation coefficients were combined in mean variation coefficients for each species and every season (Table 2).

\section{RESULTS}

\section{Weather Conditions}

The relevant spring periods in 1992 (periods 16 to 21) were on the whole warm and rather dry (Fig. 1a). The summer of 1992 (periods 31 to 37) began extraordinarily warm and ended with slightly low temperatures. There was a pronounced spell with very low precipitation from period 31 to period 34 . During the autumn periods ( 38 to 44 ) the temperature clearly decreased 
Table 2. Variability of shoot development. Mean variation coefficients based on ranks of growth rates. Growth rates for each shoot were ranked separately from smallest to largest, variation coefficients for each shoot were calculated, and finally, shoot variation coefficients were combined in mean variation coefficients for each species and every season. For abbreviations see Table 1.

\begin{tabular}{cccccccc} 
& & \multicolumn{2}{c}{$\begin{array}{c}\text { Reproductive shoots } \\
\text { spring }\end{array}$} & \multicolumn{3}{c}{ Vegetative shoots } \\
& & & summer & autumn \\
& & in situ plants & transpl. & in situ plants & transpl. & in situ plants & transpl. \\
\hline C.j. & 1992 & 0.470 & - & 0.385 & - & 0.394 & - \\
& 1993 & 0.332 & 0.329 & 0.449 & 0.455 & 0.408 & 0.411 \\
& 1994 & 0.296 & 0.161 & 0.358 & 0.333 & 0.398 & 0.507 \\
L.y. & 1992 & 0.288 & - & 0.342 & - & 0.408 & - \\
& 1993 & 0.418 & 0.434 & 0.432 & 0.410 & 0.407 & 0.429 \\
& 1994 & 0.280 & 0.341 & 0.377 & 0.369 & 0.406 & 0.434 \\
S.p. & 1992 & 0.436 & - & 0.424 & - & 0.395 & - \\
& 1993 & 0.224 & 0.226 & 0.455 & 0.370 & 0.417 & 0.395 \\
& 1994 & 0.143 & 0.237 & 0.427 & 0.332 & 0.412 & 0.430 \\
\hline
\end{tabular}

and the deviations of precipitation fluctuated around the long-term mean with the exception of period 44 , which was extremely wet ( $122 \mathrm{~mm}$ above the 20 -yr mean).

The spring of 1993 (periods 15 to 20) was again uniformly warm with one period of exceptionally high temperature (period 17; Fig. 1b). Precipitation varied around the long-term mean. The summer and autumn periods of 1993 (periods 32 to 43) are characterized by slight temperature deviations from the 20 -yr mean and generally high precipitation.

In the spring of 1994 (periods 12 to 20) extreme temperature differences occurred: the periods 15 and 16 were unusually cold while periods 13 and 18 were exceptionally warm (Fig. 1c). Precipitation during these periods was above average except for period 18 . The summer of 1994 (periods 29 to 33) was rather warm. As in 1992 there was a spell of drought from period 30 to period 32 . The beginning of autumn (periods 34 to 38 ) was again rather warm; precipitation was high.

\section{Comparison of microclimatic conditions in the original community and in the open area}

The course of the temperature $5 \mathrm{~cm}$ above soil surface was more or less identical in the original community as in the open area around the transplants (Fig. 3a). This was due to the relatively open canopy of the grassland under study. PAR (measured $5 \mathrm{~cm}$ above ground), in contrast, was generally lower and exhibited smaller fluctuations under the canopy than in the open area. The shading of the lower layers in the original community in spring periods (starting with period 14) is well documented in Fig. 3b. After mowing (period 28), the PAR values of the stand approximated again these of the open area. The curves for 1994 were similar to those depicted in Fig. 3.

\section{Variability of shoot development}

The variability of the growth rates of the different shoots within one species fluctuated around a mean variation coefficient of 0.4 (Table 2 ), but only a few trends were clearly visible. In spring and autumn the mean variation coefficients of the in situ plants were generally lower 
(a) temperature

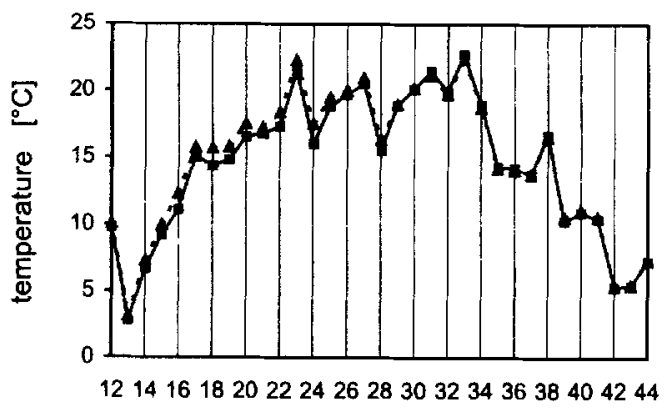

(b) PAR

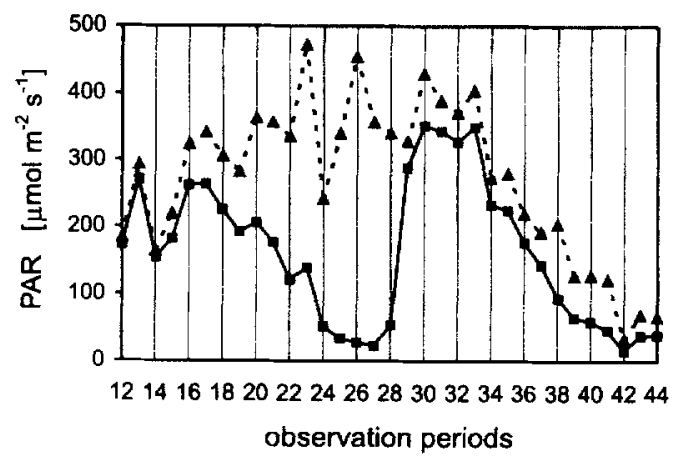

$\longrightarrow$ community $\quad \cdots \neq \cdot$ open area

than those of the transplants; in the summer the situation was reversed. Comparing the different years, the smallest variation coefficients for the spring periods occurred in 1994. For the summer periods the highest coefficients appeared in 1993. No similar pattern emerged for the autumn periods.

\section{Response of reproductive shoots in spring periods}

In the following paragraphs, it is assumed that the calculated significant relationships between weather variables and growth rates are effects of the former on the latter although these relationships do not inevitably mean causality.

\section{Transplants}

Many of the weather variables had significant effects on the growth rates of the reproductive shoots (Table 3a). Each of the three species under study generally showed a positive growth

Fig. 3. Comparison of (a) air temperature $5 \mathrm{~cm}$ above ground response to increasing temperature and (b) PAR $5 \mathrm{~cm}$ above ground from mid-March (period 12) to the end of October 1993 (period 44) in the original community and in the open area around the transplants. Mean values per period of daily means.

(Figs 4 and 5, left panels). High PAR also had a positive effect on the growth rates of Salvia and Leucanthemum (in 1994 only). While high growth rates of Centaurea coincided with moist conditions in 1994 (air humidity and precipitation), such conditions did not seem to stimulate the growth of Leucanthemum and Salvia. Daylength, a weather-independent variable, also had a positive effect on growth rates, but the corresponding $P A$-values were frequently smaller than those of the temperature variables. In summary, high growth rates of the reproductive shoots of Leucanthemum and Salvia occurred in warm and relatively dry periods with high radiation, while growth of Centaurea shoots seemed to be stimulated by warm and rather wet weather conditions.

\section{In situ plants}

For the in situ plants the situation was different; there were less significant relationships between weather variables and growth rates especially when taking into account the spring of 1992 as well (Table 3b). Only the Leucanthemum shoots in the spring of 1994 showed 
壳

웡

倦

总葛

용

ㅇㅇㅇ

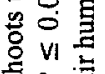

至口,

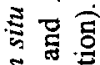

.

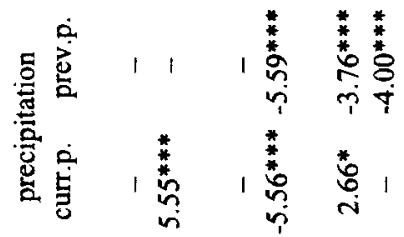

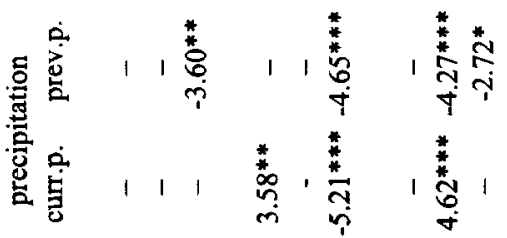

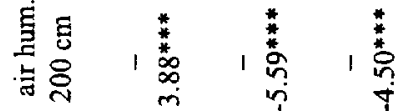

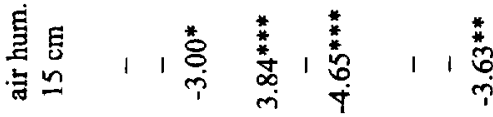

둥.

궁응

긴

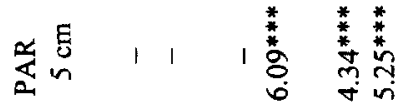

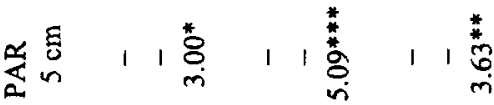
ER

政

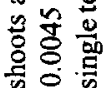

讨点

氙完

量蓄

记.

苋密要

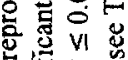

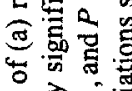

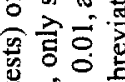

¿ v1

速高的

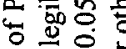

案 VI

焉必

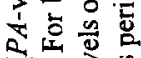

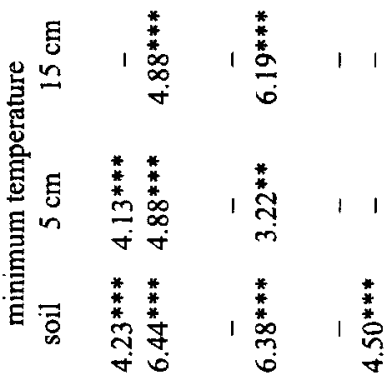

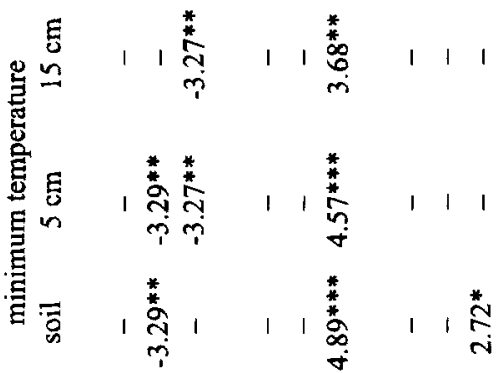

过

总总导

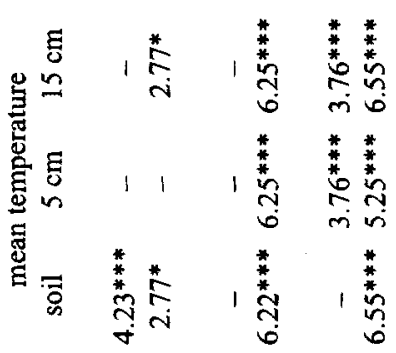

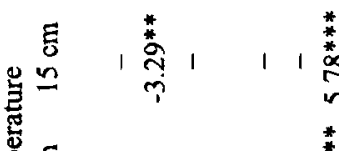

曾焉 1111

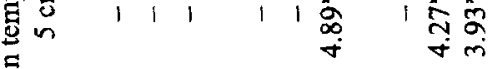

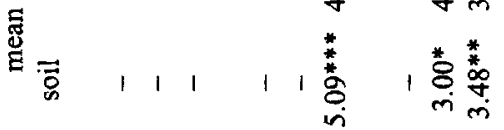

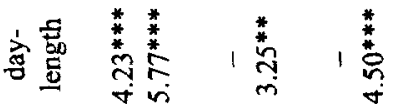

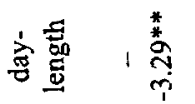

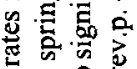

5 क⿺

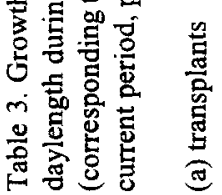

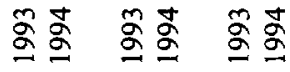

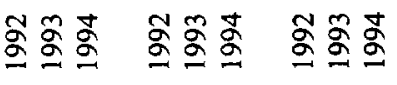

उं जे

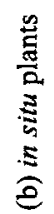

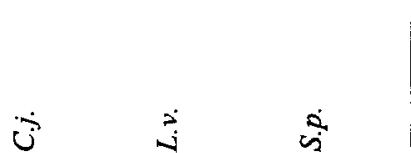



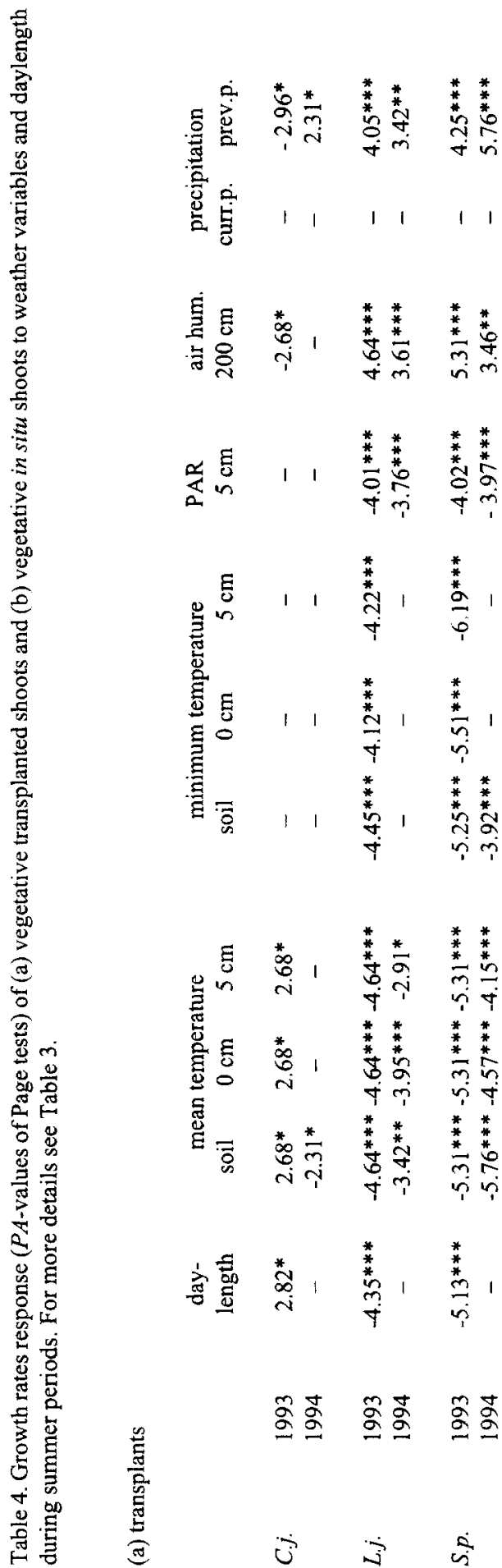

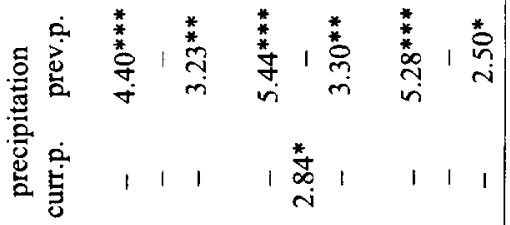

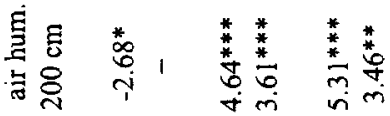

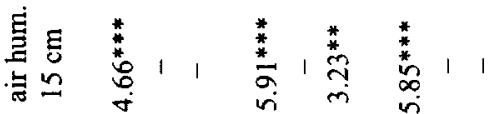

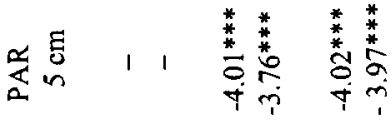

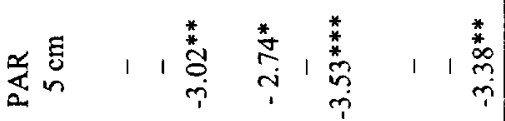
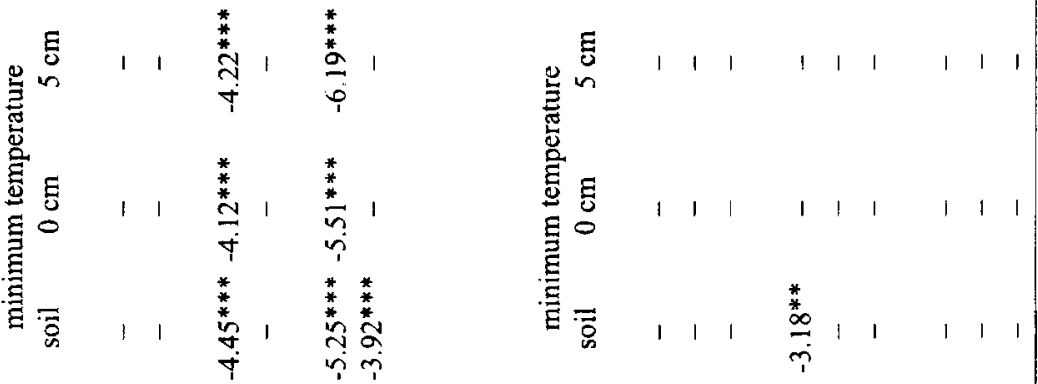

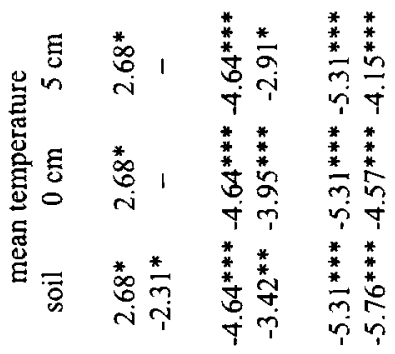

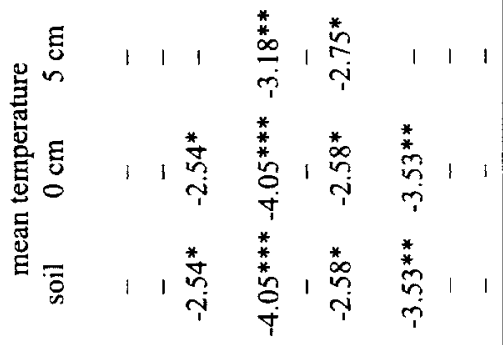

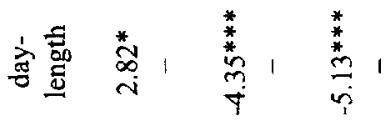

密葛
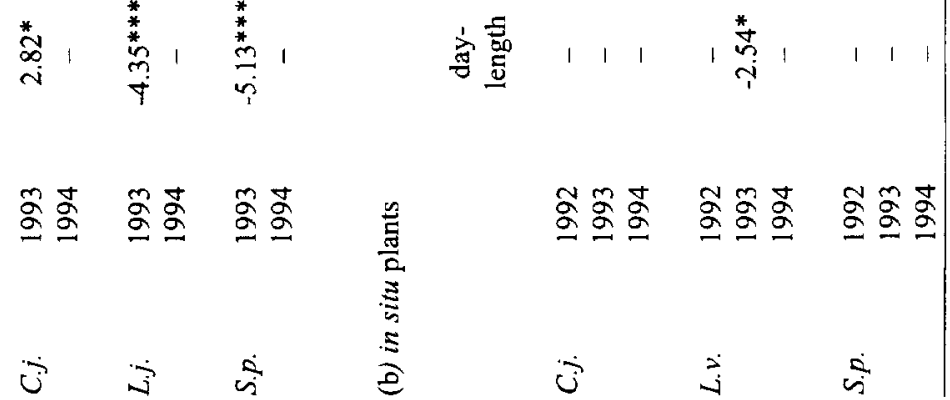

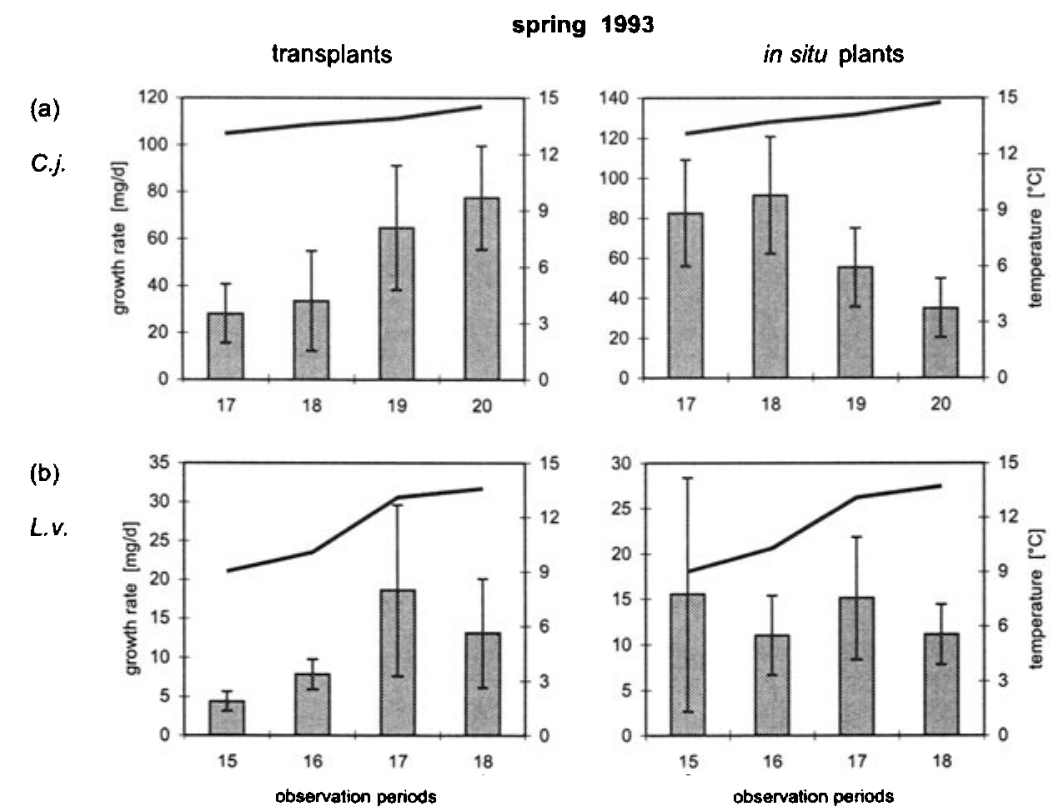

Fig. 4. Comparison of minimum soil temperature (line) and absolute growth rates (columns: mean values $\pm 1 / 2$ standard deviation) of reproductive (a) Centaurea jacea and (b) Leucanthemum vulgare shoots during the spring periods of 1993. Transplants in the left panels and in situ plants in the right panels.

spring 1994

(a)
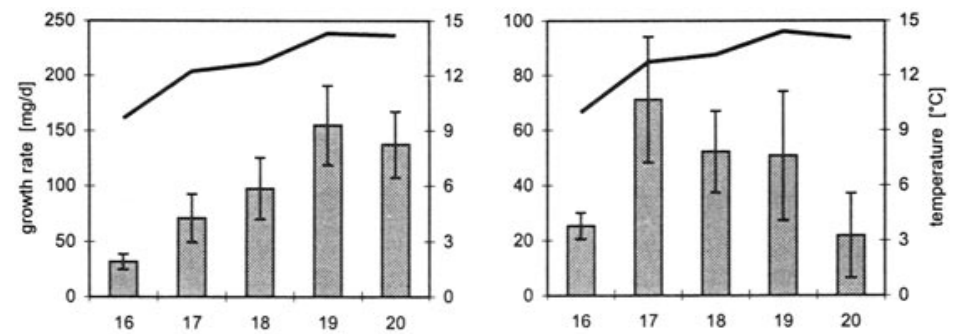

(b)
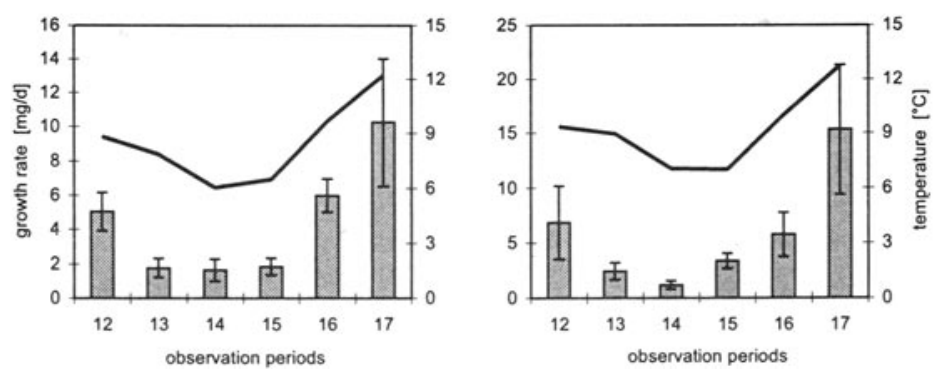

Fig. 5. Comparison of minimum soil temperature (line) and absolute growth rates (columns: mean values $\pm 1 / 2$ standard drviation) of reproductive (a) Centaurea jacea and (b) Leucanthemum vulgare shoots during the spring pe iods of 1994. Transplants in the left panels and in situ plants in the right panels. 


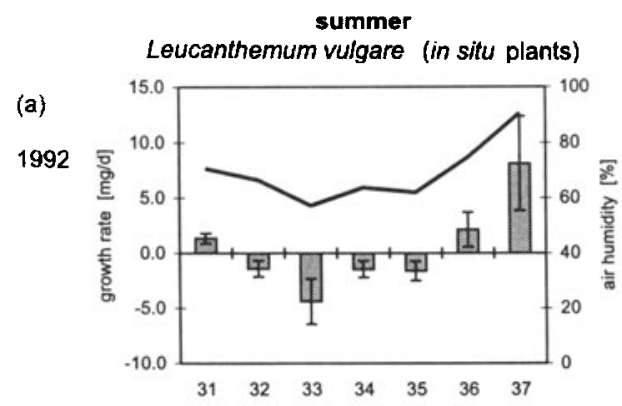

(b) 1993

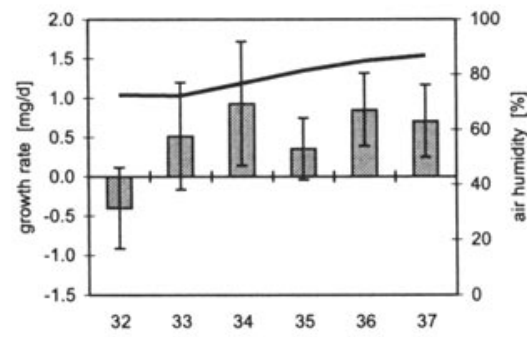

(c)

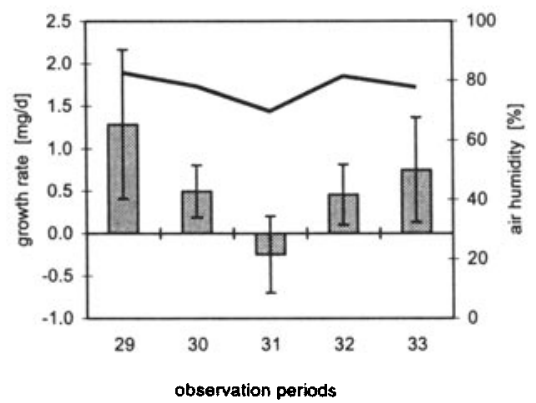

Fig. 6. Comparison of relative air humidity (line) and absolute growth rates (columns: mean values $\pm 1 / 2$ standard deviation) of vegetative Leucanthemum vulgare shoots (in situ plants) during the summer periods of (a) 1992, (b) 1993, and (c) 1994. of the in situ plants and those of the transplants (Fig. 3). Since the mowing by the farmer was less close to the ground than the cutting of the vegetation around the transplants, there were still different growth responses between the in situ plants and the transplants.

\section{Response of vegetative shoots in autumn periods}

\section{Transplants}

In the autumn periods of 1993 temperature and PAR had a significantly positive effect on the growth rates of vegetative shoots (Table 5a, Fig. 7a). Daylength had a similar effect on the growth rates as the temperature variables suggesting that declining daylength is connected with decreasing PAR and the temperature-induced winter dormancy of the plants. In the

significant responses to an extent similar to the shoots of the transplants (Fig. 5b). The negative $P A$-values of the Centaurea shoots show that their growth rates were relatively unrelated to temperature (Figs. $4 a$ and 5a,

\section{Response of vegetative shoots in summer periods}

\section{Transplants} shoots in 1993, all the vegetative shoots showed a positive growth response to elevated air humidity and/or precipitation of the previous period (Table 4a). High temperatures and high PAR coincided with dry periods and seemed to limit the growth of basal rosettes of Leucanthemum and Salvia.

\section{In situ plants}

The shoots of the in situ plants showed the same positive responses to precipitation and/or air humidity of the previous period as the shoots of the transplants (Table $4 \mathrm{~b}$ ). This response pattern was especially obvious in the summer of 1992, less clear in 1994, and not significant in 1993 (Fig. 6). The negative effect of warm and dry periods with high radiation on the growth rates was less pronounced but still detectable.

For the summer periods, mowing the stand diminished the microclimatic differences between the growing conditions 


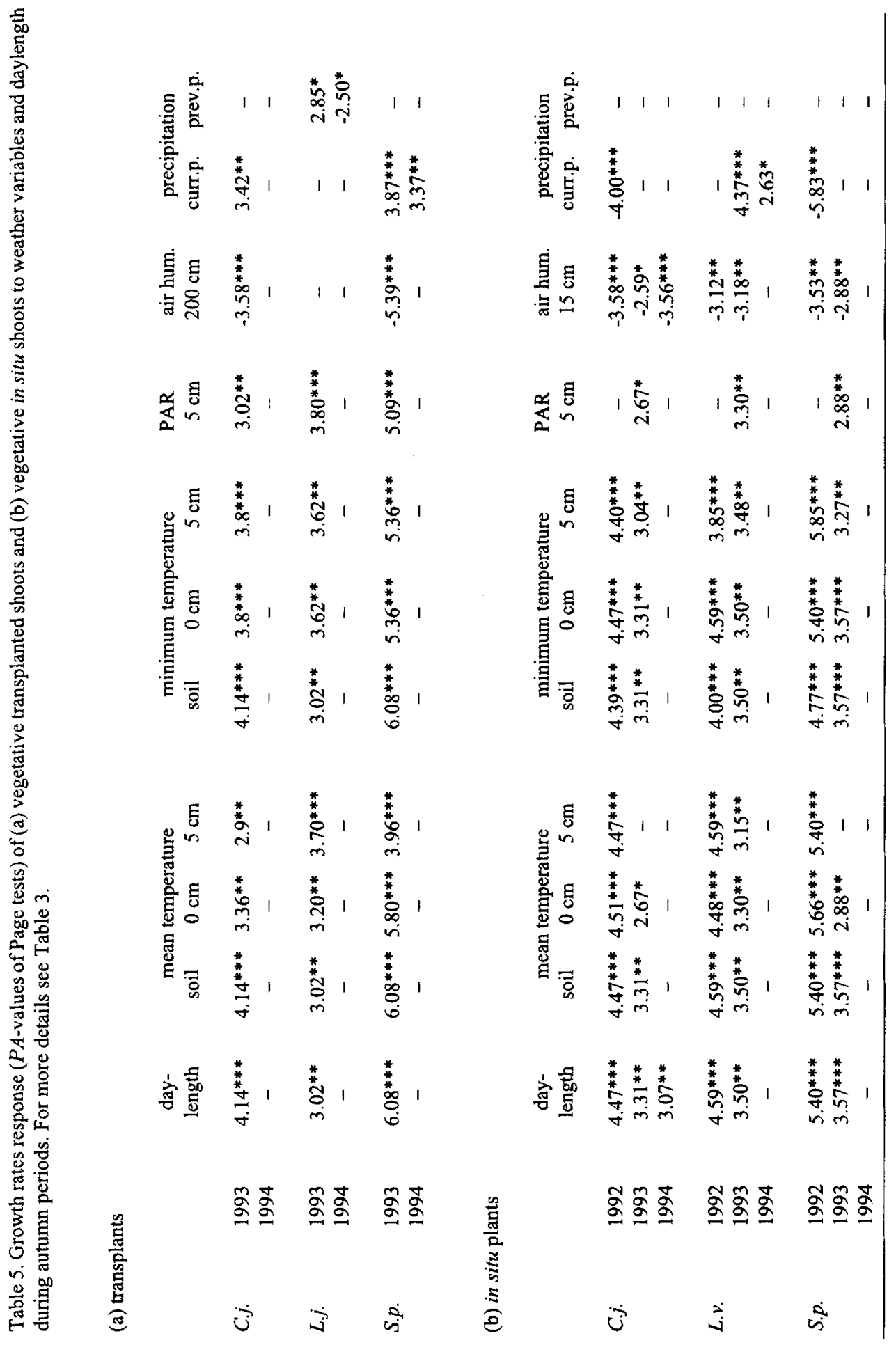


Salvia pratensis (transplants)

(a) 1993

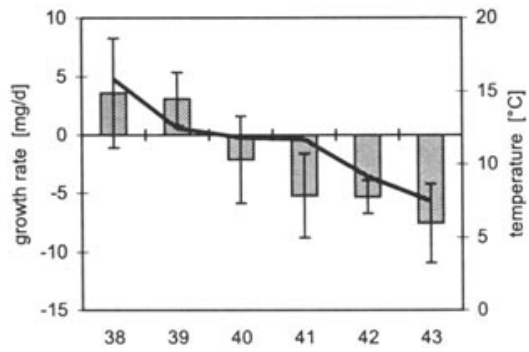

(b)

1994

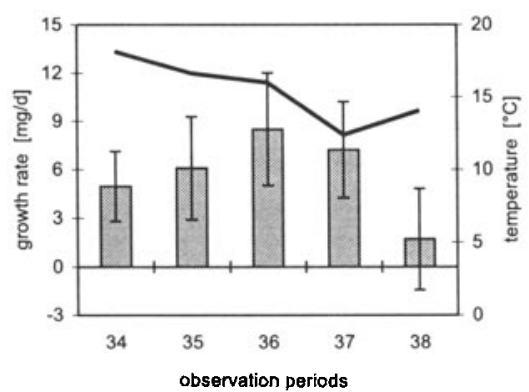

Fig. 7. Comparison of minimum soil temperature (line) and absolute growth rates (columns: mean values $\pm 1 / 2$ standard deviation) of vegetative Salvia pratensis shoots (transplants) during the autumn periods of (a) 1993 and (b) 1994. than in 1993. PAR did not seem to play a major role in 1992. For the reasons mentioned above, similar growth responses of the in situ shoots could not be observed in the autumn of 1994 .

\section{DISCUSSION}

In the spring of 1994, which was characterized by extreme temperature fluctuations, the reproductive in situ shoots of Leucanthemum suggest that their development was directly influenced by the current weather conditions, namely by temperature (Fig. 5b). Conversely, in the spring of 1992 and 1993, when the weather conditions were more moderate, the effect of the weather on the growth of the in situ plants remained rather unclear. However, the analysis of the transplants yielded more information about the potential importance of current weather conditions for the growth and development of subdominant grassland species showing that their growth rates were closely related to current weather situations. This relationship was particularly pronounced in the spring of 1994 when periods of extraordinarily low (periods 15 and 16) and high (periods 13 and 18) temperatures occurred. The development of the reproductive transplants of Leucanthemum and Salvia was affected by one warm and two cold periods, while the growth of Centaurea was influenced only by one warm and one cold period, because of its phenologically later shoot development. Consequently, the growth response to mean temperatures for Leucanthemum and Salvia was stronger than that for Centaurea (Table 3a). In the spring of 1993 no periods of exceptionally low temperature occurred. The 
growth response to temperature was therefore less pronounced than in 1994. These subtle response differences between species and years as well as the smallest developmental variability in the spring of 1994 (Table 2) illustrate the importance of extraordinary weather conditions and their synchronizing effect on the development of the reproductive transplants. In years with weather conditions closer to the average (e.g. spring of 1993), the development differed more from shoot to shoot, i.e. their development variability was more pronounced. Extraordinarily warm and unusually cold periods had major effects on the growth rates and were therefore responsible for the developmental stage and the biomass of a given shoot at a given time. As a consequence, such temperature conditions may have led to quantitative vegetation changes (cover and biomass) from year to year. These findings are consistent with numerous phenological studies that have also revealed that spring temperature (expressed as cumulative heat sum in degree-days) is the responsible variable for the timing of different phenological stages (SPARKS \& CAREY 1995, FENNER 1998, SPANO et al. 1999) and especially flowering (BEAUBIEN \& JohNSON 1994, FitTER et al. 1995, WhITE 1995, DiEKMANN 1996).

The performance of the vegetative shoots of the transplants and in situ plants in the summer and autumn periods, in the main, confirmed these results. The importance of periods with extraordinary weather conditions for plant development was again well expressed. The response of the in situ shoots of Centaurea, Leucanthemum, and Salvia to air humidity and to the precipitation of the previous period was strongest in the summer of 1992, weaker in summer 1994 and nearly zero in summer 1993. This order reflects the severity of the droughts. Accordingly, the developmental variability of the vegetative shoots was highest in the summer of 1993 (Table 2). For the species affected, spells of severe drought mean not only stress, but also disturbance in the sense of GRIME (2001). The first reactions observed were very low or even negative growth rates (Fig. 6a), i.e. basal leaves withered and no new leaves were formed. In the second step, individuals passed into secondary dormancy or they even died. During the dry periods of the summer of $1992,45 \%$ of the Leucanthemum shoots died or became dormant (KAMMER 1997). The corresponding value for Ranunculus bulbosus L. was $10 \%, 30 \%$ for Centaurea, 40\% for Knautia arvensis, and even 70\% for Anthyllis vulneraria L. All of the Salvia shoots withstood these periods. This shows that drought can be responsible for quantitative vegetation variations (density and frequency) and, in cases of local (and temporary) extinction of species, even for qualitative compositional changes. The importance of the precipitation regime as a driving force of species turnover has been demonstrated in particular for annual species in semi-arid regions (PECO 1989, FIGUEROA \& DAVY 1991, Hobbs \& MoOney 1991, Espigares \& PeCo 1995) and for shallow soils (Houle \& Phillips 1989, ROSÉN 1995, VAN DER MAAREL 1996). The present results show that even in a relatively humid climate and on deeper soils, drought as a disturbance factor can potentially exert a major influence on annual changes in species composition.

In summary, current weather conditions appear to regulate the development of the transplants throughout the growing season as well as the development of the in situ plants in the summer and autumn. In contrast, the influence of the weather conditions on the growth of the in situ plants in the spring seems to be weak. Which factors could be responsible for this discrepancy in the response level between the transplants and in situ plants in the spring periods? The most obvious factor altering growth conditions between transplants and in situ plants is the height of the surrounding vegetation. In contrast to the summer and autumn 
periods, when the vegetation remains relatively short even in the original community, the lower parts of the in situ shoots are shaded by neighbouring plants in the spring periods (Fig. 3b). The main reaction of the in situ shoots to a decreasing intensity of irradiance are small growth rates resulting in significantly smaller total shoot biomass compared to the transplanted shoots in the open area (KAMMER 1997). The reduced intensity of irradiance on the in situ shoots, however, does not explain their weak response to current temperature or moisture conditions. It is quite possible that the development of the in situ shoots is also influenced by altered light spectral quality due to the selective filtering of the surrounding vegetation. It is well known that plants can perceive the quality of light reflected from neighbours as a predictor of future competition (SCHMITT \& WULFF 1993, SMITH 1995). In the present study $R$ : FR ratios were not measured and consequently there is no direct evidence for the effect of altered light spectral quality on the development of the in situ shoots. But it is plausible that reduced R : FR ratios could have caused, for example, relatively high growth rates in the in situ shoots even during unfavourable weather conditions (for example periods 15 and 16 in Fig. 4b, right panel). In this way the neighbouring vegetation of the in situ shoots could have controlled their development and therefore weakened or even suppressed their direct growth response to weather factors. This mechanism appears to be effective especially during periods of average weather conditions (e.g. spring of 1992 and 1993), whereas in periods of more extraordinary weather conditions, their influence on shoot development is more intense (e.g. spring of 1994). This interpretation of the results supports the hypothesis put forward by Silvertown et al. (1994), STAMPfli (1995), DunNeTt \& Grime (1999), and DUNNETT \& WILLIS (2000) that states that the performance of subdominant species is primarily controlled by competition from dominant species and not directly by annual weather variations. However, the relevance of several additional issues in explaining the response differences between in situ plants and transplants should also be taken into account:

(i) Direct growth response could be masked by the developmental variability within the in situ shoots. All the transplants were of the same age while the in situ plants could be from different ontogenetic stages. Microsite variability could be higher in the original community than in the area with the transplants. This could lead to a higher between-shoot developmental variability within the in situ plants than within the transplants, obscuring the response to current weather. But, as Table 2 reveals, this was definitely not the case, quite the reverse, since in the spring periods the developmental variability of the in situ shoots was smaller than that of the transplants. According to PORS \& WERNER (1989), the genetic variability among individuals of these species seems to be more important for their development than ontogenetic or microsite variability.

(ii) The weather variables measured in the original community may be not the relevant ones for explaining the development of the reproductive in situ shoots. Or, the measured data are not representative of the microclimatic conditions for the majority of the shoots. The close developmental response of the in situ Leucanthemum shoots in the spring of 1994 showed, however, that the measured weather variables and data were in principle appropriate to detect such responses (Fig. 5b, right panel).

(iii) The transplants could have suffered from a long-lasting transplantation shock. The transplants are genetically unselected individuals compared with the established genotypes of the in situ plants, which represent only a subset of the genetic variation in the whole seed pool. 
The regular cutting of the surrounding vegetation of the transplants could have increased below-ground interference between transplants and the neighbouring plants. However, if these three aspects would have exerted major influence on the development of the transplants, one would rather expect that they would have blurred the relationship between weather conditions and growth instead of clarifying it.

The results lead to the distinction of three different impact patterns of current weather conditions on the growth of subdominant grassland species: (i) As a consequence of extraordinary weather conditions, e.g. lasting periods of drought in the summer, plants die completely or partially or pass into secondary dormancy. Such weather situations may cause quantitative or even qualitative changes in species composition by altering the density and frequency of the species involved. (ii) Major divergences from average weather conditions, such as unusually warm or cold periods in the spring, affect the growth of subdominant species and may therefore lead to quantitative annual variation of the species involved in terms of cover or biomass. (iii) Average weather conditions with slight deviations from the long-term means of the weather variables do not produce detectable direct growth responses and therefore average weather conditions are not key factors for year-to-year variations in the quantitative and qualitative performance of subdominant species.

The present study shows that the developmental response of plants to weather is highly complex. For a better understanding of vegetation dynamics more research is required to ascertain the importance of the different response components for year-to-year vegetation changes. Moreover, the impact of the surrounding vegetation of a shoot on its growth and development has to be investigated in order to understand the dynamics of subdominant species.

Acknowledgements: I thank David M. Newbery, Otto Hegg, Andreas Stampfli, and Jean-Pierre Airoldi for their helpful discussions and comments on the manuscript, Jürg Hüsler for statistical advice, Marc Rosset and Christian Bühler for their technical assistance in microclimatic measurements and plant cultivation (all Bern $\mathrm{CH}$ ). Furthermore, I would like to show my appreciation to Ian Woodward (Sheffield GB) and Gill Rapson (Palmerston NZ) for their valuable comments on an earlier version of the manuscript. Financial support was obtained from the Swiss Confederation (Swiss Agency for the Environment, Forests and Landscape) and the Canton of Bern (SEVA-Lotteriefonds),

\section{REFERENCES}

ALBERTSON F.W. \& TOMANEK G.W. (1965): Vegetation changes during a 30-year period in grassland communities near Hays, Kansas. Ecology 46: 714-720.

BEAUBIEN E.G. \& JOHNSON D.L. (1994): Flowering plant phenology and weather in Alberta, Canada. Int. $J$. Biometeorol. 38: 23-27.

COLlins S.L., BRADFORD J.A. \& SIMS P.L. (1987): Succession and fluctuation in Artemisia dominated grassland. Vegetatio 73: 89-99.

CYTEL (1995): StatXaci for Windows. Statistical software for exact nonparametric inference. Cytel Software Corporation, Cambridge.

DANIEL W.W. (1990): Applied nonparametric statistics. Ed. 2. PWS-Kent, Oxford.

DIEKMANN M. (1996): Relationship between flowering phenology of perennial herbs and meteorological data in deciduous forests of Sweden. Canad. J. Bot. 74: 528-537.

DIERSCHKE H. (1985): Experimentelle Untersuchung zur Bestandesdynamik von Kalkmagerrasen (Mesobromion) in Südniedersachsen. I. Vegetationsentwicklung auf Dauerflächen 1972-1984. In: SCHREIBER K.F. (ed.), Sukzession auf Grünlandbrachen, Münstersche Geogr. Arbeiten 20: 9-23. 
DUNNETT N.P., WILLIS A.J., HUNT R. \& GRIME J.P. (1998): A 38-year study of relations between weather and vegetation dynamics in road verges near Bibury, Gloucestershire. J. Ecol. 86: 610-623.

DUNNETT N.P. \& GRIME J.P. (1999): Competition as an amplifier of short-term vegetation responses to climate: an experimental test. Funct. Ecol. 13: 388-395.

DUNNETT N.P. \& WILLIS A.J. (2000): Dynamics of Chamerion angustifolium in grassland vegetation over a thirty-nine-year period. $P l$. Ecol. $148: 43-50$,

ELLENBERG H. (1996): Vegetation Mitteleuropas mit den Alpen. Ed. 5. Ulmer, Stuttgart.

ESPIGARES T. \& PECO B. (1995): Mediterranean annual pasture dynamics: impact of autumn drought. J. Ecol. 83: $135-142$.

FENNER M. (1998): The phenology of growth and reproduction in plants. Perspect. Pl. Ecol. Evol. Syst. 1: $78-91$.

FigueroA M.E. \& DAVy A.J. (1991): Response of mediterranean grassland species to changing rainfall. J. Ecol. 79: 925-941.

FITTER A.H., FITTER R.S.R., HARRIS I.T.B. \& Williamson M.H. (1995): Relationships between first flowering date and temperature in the flora of a locality in central England. Funct. Ecol. 9: 55-60.

GRIME J.P. (2001): Plant strategies, vegetation processes, and ecosystem properties. Ed. 2. Wiley, Chichester.

Herben T., KRAHUleC F., HADINCOVÁ V. \& PECHÁCKOVÁ S. (1995): Climatic variability and grassland community composition over 10 years: separating effects on module biomass and number of modules. Funct. Ecol. 9: 767-773.

HOBBS R.J. \& MOONEY H.A. (1991): Effects of rainfall variability and gopher disturbance on serpentine annual grassland dynamics. Ecology 72: 59-68.

HOULE G. \& PHILLIPS D.L. (1989): Seasonal variation and annual fluctuation in granite outcrop plant communities. Vegetatio 80: 25-35.

KAMMER P.M. (1997): Räumliche, zeitliche und witterungsbedingte Variabilität eines Trespen-Halbtrockenrasens (Mesobromion) im Schweizer Mittelland (Spatial, temporal and weather influenced variability of a Bromus erectus-dominated grassland in the Swiss midlands). Diss. Bot. 272: $1-255$.

KAMMER P.M. (1998): Erfolgskontrolle im Naturschutz: Eine Methode für die repräsentative Überwachung von Pflanzenbeständen mit Dauerflächen. Z. Ökol. Naturschutz 7: 99-109.

LEGENDRE P. \& LEGENDRE L. (1998): Numerical ecology. Ed. 2. Developments in environmental modelling 20. Elsevier, Amsterdam.

Milchunas D.G., LAUENROTH W.K., ChapMAN P.L. \& KAZEMPOUR M.K. (1989): Effects of grazing, topography, and precipitation on the structure of a semiarid grassland. Vegetatio $80: 11-23$.

PECO B. (1989): Modelling mediterranean grassland dynamics. Vegetatio 83: 269-276.

PORS B. \& WERNER P.A. (1989): Individual flowering time in a Goldenrod (Solidago canadensis): field experiment shows genotype more important than environment. Amer. J. Bot. 76: 1681-1688.

RoSÉN E. (1995): Periodic droughts and long-term dynamics of alvar grassland vegetation on Öland, Sweden. Folia Geobot. Phytotax. 30: 131-140.

Sala O.E., Parton W.J., JoYce L.A. \& Lauenroth W.K. (1988): Primary production of the Central Grassland region of the United States. Ecology 69: 40-45.

SCHMITT J. \& WULFF R.D. (1993): Light spectral quality, phytochrome and plant competition. Trends Ecol. Evol. 8: 47-51.

SILVERTOWN J., DODD M.E., MCCONWAY K., POTTS J. \& CRAWLEY M. (1994): Rainfall, biomass variation, and community composition in the Park Grass Experiment. Ecology 75: 2430-2437.

SMITH H. (1995): Physiological and ecological function within the phytochrome family. Annual Rev. Pl. Physiol. 46: 289-315.

SpANo D., Cesaraccio C., DUCE P. \& SNYDER R.L. (1999): Phenological stages of natural species and their use as climate indicators. Int. J. Biometeorol. 42: 124-133.

SPARKS T.H. \& CAREY P.D. (1995): The responses of species to climate over two centuries: an analysis of the Marsham phenological record 1736-1947.J. Ecol. 83: 321-329.

STAMPfLI A. (1995): Species composition and standing crop variation in an unfertilized meadow and its relationship to climatic variability during six years. Folia Geobot. Phytotax. 30: 117-130.

STOUTJESDIJK P. \& BARKMAN J.J. (1992): Microclimate, vegetation and fauna. Opulus, Knivsta. 
TILMAN D. \& EL HADDI A. (1992): Drought and biodiversity in grasslands. Oecologia 89: 257-264.

VAN DER MAAREL E. (1996): Pattern and process in the plant community: fifty years after A.S. Watt. J. Veg. Sci. 7: 19-28.

WATT A.S. (1971): Factors controlling the floristic composition of some plant communities in Breckland. In: DUFFEY E. \& WATT A.S. (eds), The scientific management of animal and plant communities for conservation, Symposium of the British Ecological Society 11, Blackwell, Oxford, pp. 137-152.

WHITE L.M. (1995): Predicting flowering of 130 plants at 8 locations with temperature and day-length. J. Range Managem. 48: 108-114.

Received 24 May 2001, revision received 6 March 2002, accepted 4 June 2002 